\title{
A córnea não é um pedaço de plástico
}

\author{
Cristina Muccioli, Mauro Campos, Mauro Goldchmit, Paulo E.C. Dantas, Samir J. Bechara, Vital Paulino Costa
}

A córnea é uma estrutura anesférica e transparente que juntamente com a esclera compõe a túnica fibrosa do olho. Algumas características desta estrutura, como ser não-pigmentada, avascular, ter epitélio não queratinizado, conter fibras nervosas amielínicas e forma convexa permitem-na desempenhar funções ópticas importantes. Além disso, as suas cinco camadas, epitélio, camada de Bowman, estroma, membrana de Descemet e endotélio, com suas características morfológicas próprias, confere estrutura e proteção ao olho, graças à sua resistência mecânica alta.

Cada uma das camadas da córnea parece ter características mecânicas próprias, conferidas pelas junções intercelulares e complexos de adesão, como no epitélio, ou elasticidade pequena, como a da camada de Bowman, o que faz com que a córnea anterior se deforme proporcionalmente mais intensamente nos casos de edema de córnea. O estroma corresponde a $90 \%$ da espessura corneal, sendo composto por colágeno produzido pelos ceratócitos, células que também produzem proteoglicanos e glicoproteínas da matriz extracelular. A membrana de Descemet é bastante elástica e o endotélio corneano é pouco resistente, formado por uma única camada de células.

Após um trauma, como em um PRK ou Lasik, ocorre uma resposta cicatricial que envolve regeneração epitelial, apoptose e necrose de ceratócitos, presença de células inflamatórias resultando em hiperplasia epitelial, ativação celular e produção de fibras colágenas novas, constituindo-se um tecido cicatricial. Além disso, o trauma mecânico pode levar a uma alteração estrutural das cadeias moleculares alterando as propriedades mecânicas da córnea. Assim, as características mecânicas da córnea poderiam estar alteradas após um trauma, tanto pela presença de tecido cicatricial como pelo desarranjo estrutural de sua matriz extracelular. Atualmente, sob o ponto de vista clínico é difícil medir o processo cicatricial da córnea. Porém, as alterações que o trauma e a cicatrização produzem sobre as propriedades mecânicas da córnea tem sido estudadas clinicamente. $\mathrm{O}$ fato importante é que propriedades biomecânicas não somente da córnea como também de todo o olho influenciam os resultados de vários procedimentos oftalmológicos como medidas de pressão ocular e cirurgias refrativas. Trabalho recente da Universidade de Grete, coloca a resistência ocular como fator de risco para desenvolvimento de degeneração macular senil.

Alguns conceitos em biomecânica ocular tem sido apresentado aos oftalmologistas. A córnea e esclera demonstram características visco-elásticas complexas. A propriedade de elasticidade representa a capacidade de deformação de um material, e é medido pela sua deformação em função de uma força que é aplicada. Se a deformação for diretamente proporcional à força, independente do tempo ou da freqüência com que a força é aplicada, fala-se em elasticidade. A viscosidade é dependente do tempo e frequiência. Para exemplificar, seria como introduzir uma colher em uma jarra de mel, quanto maior a velocidade de deslocamento da colher, maior será a resistência (material muito viscoso). Em oftalmologia utiliza-se o termo histeresis corneal, a capacidade da córnea de absorver e dissipar energia. Até algum tempo, esta propriedade da córnea era referida simplesmente como módulo de Young, uma medida da elasticidade da córnea.

Cada indivíduo tem sua córnea com características mecânicas próprias, com menor ou maior capacidade de tolerar, por exemplo, a pressão ocular. Assim, pessoas que tivessem uma medida reduzida de histeresis corneal apresentariam deformação mais acentuada da córnea, como efeito da pressão ocular. Assim, em uma cirurgia de Lasik, a histeresis ou medida de resistência da córnea estaria reduzida pelo afinamento do tecido (questionado por alguns) e também pela criação da lamela (ou flap) o que poderia explicar o aparecimento das ectasias e as mudanças nas medidas de pressão ocular pelo tonômetro de Goldmann entre o pré e pós-operatório. Paralelamente pode-se estimar as implicações destes conceitos em doenças como o ceratocone e também no glaucoma, onde a precisão da tonometria de aplanação pode ser afetada pela resistência corneal. Artigo recente tem demonstrado os efeitos da rigidez corneal, ou do módulo de Young na tonometria de aplanação de Goldman, podendo levar a medidas com desvios de cerca de $15 \mathrm{mmHg}$ em um olho com pressão ocular estimada de $20 \mathrm{mmHg}$.

Como visto acima, a medida in vivo das propriedades mecânicas da córnea tem importância pelo menos em duas áreas importantes da oftalmologia, cirurgia refrativa e glaucoma.

Alguns equipamentos estão disponíveis comercialmente que pretendem medir em pacientes, a resistência da córnea e, a partir deste valor, corrigir a pressão ocular de Goldmann. Em cirurgia refrativa, algum cirurgião tem defendido a possibilidade de utilizar esta medida na seleção de candidatos a cirurgia refrativa, partindo-se da premissa que córneas menos resistentes teriam maior tendência a desenvolver ectasia pósoperatória.

A experiência inicial com estas tecnologias permite observar grande variabilidade entre as medidas, em diferentes horários do dia e entre indivíduos topográfica e paquimetricamente considerados normais. Em ceratocones desenvolvidos as medidas de histeresis estão realmente diminuídas mas em ceratocones subclínicos (os casos que realmente trazem dúvidas em relação à seleção para cirurgia refrativa) as medidas são incon- 
clusivas. Vários subgrupos e condições patológicas como diabéticos, portadores de edema corneal e opacidades corneanas têm sido estudados para verificar a aplicação clínica real desta tecnologia. Sabe-se que o Lasik reduz a medida de rigidez corneal entre o pré e pós-operatório.

Porém, em um estudo preliminar prospectivo de Lasik versus PRK em portadores de ametropias de igual magnitude e no mesmo indivíduo, não se observam diferenças pós-operatórias entre os olhos operados com as diferentes técnicas, o que não é compatível com alguns conceitos apresentados pelos estudiosos na área de mecânica corneal.

$\mathrm{Na}$ área de glaucoma, também há dúvidas sobre o real benefício desses instrumentos do ponto de vista clínico e vários estudos serão necessários para investigar a capaci- dade destes aparelhos de determinar a PIO real. No entanto, estudos clínicos em andamento sugerem que a medida de pressão ocular corrigida por características mecânicas da córnea agrega valor ao controle pressórico de portadores de glaucoma de pressão normal, em hipertensos oculares e também em pacientes operados de Lasik.

Como todo procedimento novo e, provavelmente com potencial clínico bastante relevante, a avaliação clínica das propriedades mecânicas do globo ocular tem provocado bastante euforia entre seus adeptos. Novos equipamentos de medida destas propriedades estão sendo estudados e seus resultados preliminares divulgados rapidamente o que pode provocar conclusões precipitadas. Cabe a nós oftalmologistas e pesquisadores em ciências visuais selecionar os cantos e as sereias. 